\title{
PEMANFAATAN MEDIA SOSIAL SEBAGAI MEDIA KOMUNIKASI KOMUNITAS PUSTAKAWAN HOMOGEN DALAM RANGKA PEMANFAATAN BERSAMA KOLEKSI ANTAR PERGURUAN TINGGI
}

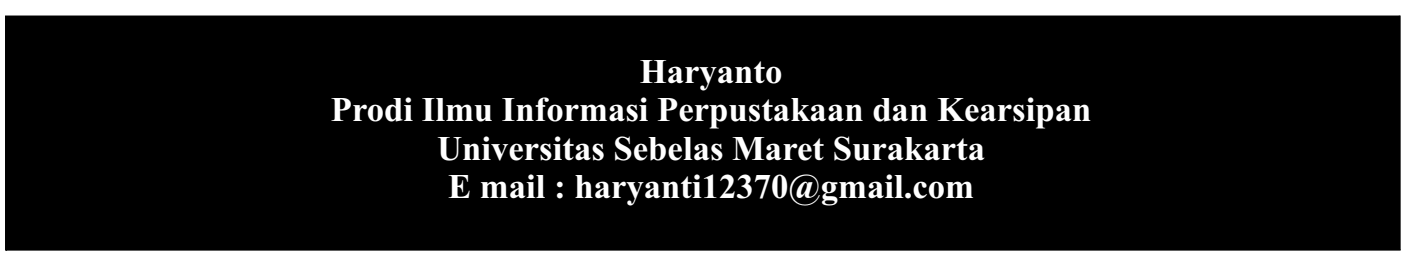

Abstrak. Karya ilmiah ini merupakan hasil analisis yang mengulas media sosial sebagai media yang sangat efektif dijadikan media komunikasi komunitas pustakawan dari perpustakaan yang sama program studinya (homogeneity) antar perguruan tinggi. Tujuan dari analisis ini adalah terciptanya komunikasi antar pustakawan homogen antar perguruan tinggi sehingga dapat saling mendukung dalam penyediaan koleksi. Dalam dunia perpustakaan, keterbatasan koleksi dihadapi oleh hampir semua perpustakaan, sehingga diperlukan usaha seperti sharing koleksi (resources sharing). Dengan media sosial dapat dimungkinkan membuat komunitas-komunitas sejenis atau homogen sehingga dapat berkomunikasi secara cepat untuk sharing koleksi. Dalam memanfaatkan media

sosial untuk resources sharing perpustakaan perguruan tinggi, agar efektif diperlukan beberapa hal diantaranya kesamaan komunitas jurusan /homogen, admin utama pengendali, kesepakatan resources sharing, no rekening Bank, jasa ekspedisi, serta MoU.

Keyword: Koleksi, Social Network, Resources Sharing, Perpustakaan PT

Abstract. This scientific paper is resulted from an analysis about social media as an effective media for communication between librarian communities of the same study program (homogeny) from different universities. The analysis aims to create communication between homogenous librarians from different universities so that they can support each other in the provision of library collections. In the world of libraries, collection limitation is faced by almost all libraries, therefore effort like resources sharing is required. The use of social media enables the homogeneous communities to communicate quickly to share collections. In order to effectively use social media for resources sharing, the librarian communities should several things in common which include homogeneity, main admin control, resources sharing agreement, bank account, forwarding service provider, and memorandum of understanding (MoU).

Keywords:Collection, Social Network, Resources Sharing,University Library 


\section{A. Pendahuluan}

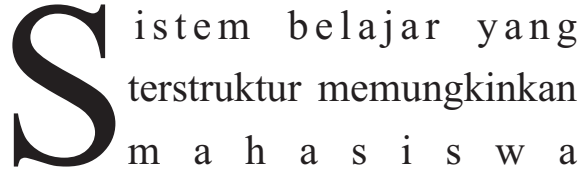

mengembangkan diri di perguruan tinggi melalui informasi yang dimiliki seluas luasnya dengan berbagai sumber informasi, sehingga informasi berupa koleksi yang dimiliki perpustakaan di perguruan tinggi sangatlah berpengaruh dalam pendidikan mahasiswa. Hampir semua perpustakaan mengalami keterbatasan dalam hal koleksi perpustakaan, tidak terkecuali perguruan tinggi, meskipun anggaran setiap tahun terus ditingkatkan tidak akan mampu memenuhi kebutuhan informasi yang diperlukan mahasiswa karena perkembangan kebutuhan informasi serta keterbatasan sumber daya. Hal tersebut seharusnya tidak menjadi suatu permasalahan jika perpustakaan yang homogen atau sama jenisnya melakukan komunikasi untuk saling melengkapi sengan cara sharing resources atau berbagi sumber daya koleksi, perpustakaan yang homogen dalam perguruan tinggi adalah perpustakaan yang mempunyai bidang studi yangs sama, misalnya sama-sama kelompok Fakultas Ekonomi, kelompok Fakultas Hukum, kelompok Fakultas Sospol atau kelompok Fakultas Teknik, dan sebagainya. Kesamaan jurusan dengan perbedaan lokasi universitas dimungkinkan akan dapat saling meleng- kapi dengan adanya pemanfaatan bersama koleksi, misalkan dengan layanan fotokopi dari jauh atau saling pinjam antar perpustakaan. Permasalahan yang utama timbul yaitu diperlukan media komunikasi yang mampu membuat suatu komunitas atau group yang homogen sehingga akan dapat lebih maksimal dalam sharing informasi karena adanya kesamaan kebutuhan informasi.

Perkembangan teknologi mendasari lahirnya media sosial yang saat ini mengubah perilaku komunikasi dan sosial dalam masyarakat profesi. Munculya media sosial menjadikan komunikasi dapat dilakukan seperti tanpa batas jarak dan waktu. Dengan media sosial dapat dimungkinkan membuat komunitas-komunitas pustakawan dengan latar belakang program studi yang sama atau homogen sehingga dapat saling support atau sharing, dengan berbagai kelebihan-kelebihan tersebut, media sosial saat ini marak dijadikan tempat pustakawan untuk membentuk group atau komunitas dengan berbagai tujuan, tujuan tersebut diantaranya sebagai ajang silaturahmi, komunikasi, sharing dan juga pengembangan diri. Situs jejaring sosial didefinisikan sebagai layanan berbasis web yang memungkinkan individu untuk membangun profil publik, dengan jejaring sosial dapat diatur daftar pengguna lain dengan siapa mereka berbagi koneksi, melihat profil publik, dengan jejaring sosial dapat diatur daftar pengguna lain- 
lain dengan siapa mereka berbagi koneksi, melihat dan menunjukkan daftar koneksi yang dimiliki dan yang dibuat oleh orang lain dalam sistem. (Boyd dan Ellison, 2007). Powel mendefinisikan jaringan media sosial sebagai sebuah komunitas yang terhubung melalui persahabatan, nilai-nilai, hubungan, ide dan pekerjaan.(Powell, 2009). Seufert mendefinisikan situs jejaring sosial sebagai sejumlah orang, sumber daya yang terhubung untuk mengumpulkan pengetahuan untuk tujuan menciptakan suatu nilai. Konsep jejaring sosial adalah salah satu dari alat-alat Web 2.0, yang juga membentuk dasar perpustakaan 2.0.(Seufert et al,1999). Andreas Kaplan dan Michael Haenlein mendefinisikan media sosial sebagai "sebuah kelompok aplikasi berbasis internet yang dibangun atas dasar ideologi dan teknologi Web 2.0, dan yang memungkinkan pertukaran informasi. (Kaplan, Andreas, Michael, 2010)

Dari berbagai definisi diatas dapat disimpulkan bahwa media sosial dalah web platform di mana orang-orang dari budaya yang berbeda pengaturan dapat terhubung dan berinteraksi satu sama lainnya untuk bertukar informasi.

Saat ini banyak group-group di media sosial seperti facebook berupa forum komunikasi pustakawan dengan dasar komunitas sama-sama pustakawan, namun masih sedikit forum komunikasi pustakawan dengan latar belakang sejenis misalnya forum komunikasi pustakawan bidang hukum atau lainnya, padahal dengan adanya forum komunikasi tersebut akan mempunyai banyak sisi positif bagi masing masing anggota. Untuk itu perlu ditelaah dalam karya ilmiah ini manfaat serta berbagai keuntungan dalam pemanfaatan media sosial sebagai media komunikasi komunitas pustakawan homogen dalam rangka pemanfaatan bersama koleksi di perguruan tinggi. Dalam karya ilmiah ini penulis menganalisis salah satu media sosial yang masih menjadi nomor satu di Indonesia dalam penggunaannya yaitu Facebook. Facebook telah memiliki lebih dari 750 juta pengguna aktif pada tahun 2011. (Facebook, 2011), jadi merupakan media social networking dengan pengguna terbesar di seluruh dunia.

\section{B. Pembahasan}

Media sosial merupakan situs dimana setiap orang bisa membuat web page pribadi, kemudian terhubung dengan teman-teman untuk berbagi informasi dan berkomunikasi media sosial terbesar antara lain Facebook, Myspace, dan Twitter. Jika media tradisional menggunakan media cetak dan media broadcast, maka media sosial menggunakan internet. Media sosial mengajak siapa saja yang tertarik untuk berpertisipasi dengan memberi kontribusi i 
dan feedback secara terbuka, memberi komentar, serta membagi informasi dalam waktu yang cepat dan tak terbatas. Perkembangan teknologi informasi menjadikan pertumbuhan gadget makin beragam canggih dan murah, maka media sosial pun ikut tumbuh dengan pesat karena dapat diakses dari berbagai gadget tersebut. Kini untuk mengakses facebook atau twitter misalnya, bisa dilakukan dimana saja dan kapan saja hanya dengan menggunakan sebuah smartphone, handphone atau tableth. Demikian cepatnya orang bisa mengakses media sosial mengakibatkan terjadinya fenomena besar terhadap arus informasi tidak hanya di negara-negara maju, tetapi juga di Indonesia. Karena kecepatannya media sosial juga mulai tampak menggantikan peranan media massa konvensional dalam menyebarkan beritaberita dan media berkomunikasi baik personal, berkelompok atau komunitas.

berkelompok atau komunitas.

Dalam dunia perpustakaan, keterbatasan koleksi dihadapi oleh hampir semua perpustakaan, keterbatasan koleksi disebabkan karena jumlah judul tema tertentu yang beredar di pasaran yang cukup banyak dan tidak mungkin sebuah perpustakaan memiliki semua karena keterbatasan anggaran, padahal permintaan jenis buku baru dari mahasiswa terus meningkat.sehingga pustakawan harus berkreasi untuk menyelesaikan permasalahan keterbatasan koleksi ini. Resources sharing perpustakaan merupakan suatu usaha berbagi sumber daya berupa koleksi perpustakaan, di dasari oleh kerjasama antar perpustakaan dengan saling berbagi koleksi untuk memenuhi kebutuhan pemustaka. Kendala dalam resources sharing terletak pada kurangnya komunikasi antar pustakawan dengan jurusan yang homogen sehingga ketika sewaktu waktu penelusuran informasi diperlukan karena koleksi tidak dimiliki maka pustakawan akan segera membuat status dalam group media social yang khusus bagi jurusan tersebut agar mendapat perhatian dari pustakawan lain yang sejenis dan diharapkan mempunyai koleksi yang di inginkan, jadi media sosial selain sebagai merupakan media yang efektif dan inovatif dalam menghubungkan perpustakaan dengan pemustaka. (O'Dell S., 2010), juga efektif dan inovatif dalam menghubungkan antar pustakawan dalam penelusuran informasi dan resources sharing.

Media sosial sering kali dipakai pustakawan dengan tujuan menjadi bagian dari komunitasnya. (De Rosa etal., 2007) atau mempromosikan layanan dan kegiatan perpustakaan. (Charnigo \& Barnett-Ellis,2007; Hendrix, Chiarella, Hasman, Murphy, \& Zafron,2009). Sampai saat ini banyak sekali groupgroup dalam media sosial yang telah dibentuk pustakawan berdasarkan profesi, jenis perpustakaan, minat, akan tetapi ma- 
masih minim group yang didasari oleh satu bidang keilmuan seperti hukum, ekonomi atau teknik, padahal jika dioptimalkan dalam kerjasama resources sharing antar perpustakaan perguruan tinggi akan meningkatkan layanan kepada pemustaka dalam memenuhi kebutuhan informasi.Sharing pengetahuan merupakan aspek penting untuk perpustakaan menggunakan media sosial sejak perpustakaan mempunyai peranan penting dalam sharing pengetahuan. (MacAdam, 1998). Media sosial seperti facebook sangat efektif dipakai sebagai media komunikasi karena memenuhi beberapa akspek, diantaranya;

1. Mampu membuat group komunitas

2. Diakses melalui internet dengan komputer maupun berbagai macam gadget

3. Dapat saling berkirim, share berbagai jenis file

4. Terdapat log atau data komunikasi

5. Mampu sebagai media promosi koleksi yang dimiliki perpustakaan dengan cara memposting koleksi tersebut

Dalam membentuk suatu komunitas atau group di media sosial agar efektif dan mendukung penelusuran informasi dan share informasi pada suatu group perpustakaan yang homogen diperlukan berbagai hal diataranya :

1. Kesamaan komunitas jurusan / homogen, membuat group atau komunitas hendaklah didasari kesesuaian dengan bidangnya sama-sama bidang misalnya sama-sama bidang ekonomi, sama-samabidang hukum, sama-sama bidang teknik, sehingga ketika ada permintaan informasi dari pemustaka dan tidak dimiliki perpustakan

2. Admin utama, dalam sebuah group atau komunitas diperlukan admin atau leader yang bertugas memantau dan mengiformasikan serta membina anggota group. Jika terdapat informasi dari anggota yang membutuhkan yang tidak $\mathrm{sampai,}$ t ugas a d m in mengingatkan kepada anggota lain.

3. Kesepakatan resources sharing. Dalam resources sharing agar kegiatan berjalan dengan lancar sebelumnya harus dibuat kesepakatan, sharing material koleksi dapat dilaksanakan dengan pinjam meminjam koleksi atau fotokopi serta penghitungan biaya yang dibutuhkan. Hal ini sangat penting karena anggota komunitas juga ingin memastikan keamanan koleksi yang dimilikinya meskipun harus resources sharing. Jadi dapat dimungkinkan perpustakaan yang share koleksinya memfotokopikan koleksinya dengan membebankan biaya pada perpustakan yang membutuhkan, atau perpustakaan yeng share koleksi meminjamkan koleksinya untuk difotokopi.

4. Nomor rekening Bank. Dalam resources sharing seringkali pihak yang membutuhkan diharuskan mengganti biaya fotokopi, jika terdapat nomor rekening masing masing perpustakaan maka transaksi akan lebih mudah dan jelas karena dapat saling memantau.

5. Jasa ekspedisi. Dalam share informasi kepada perpustakaan lain yang jaraknya bisa antar kota maupun antar pulau, hasil fotokopi seringkali harus dikirimkan mela- 
lui jasa ekspedisi, untuk itu perlu juga disepakati seluruh anggota jasa ekspedisi apa yang dipakai, sehingga memudahkan dalam pengiriman antar kota atau antar pulau.

6. Nota kesepahaman (memorandum of understanding atau $M o U$ ). Dalam suatu komunitas perpustakaan perguruan tinggi yang sama jurusannya atau sejenis atau homogen, diperlukan waktu tertentu untuk merumuskan kebijakan dan menuangkan dalam MoU atau memory of understanding atau nota kesepakatan, hal ini sangat penting karena dengan adanya MoU akan meningkatkan nilai prestise sebuah perpustakaan karena mempunyai nota kesepakatan sharing koleksi dengan perpustakaan lain, sehingga nilai akreditasi akan meningkat dan menimbulkan kemajuan bersama dalam memenuhi kebutuhan informasi mahasiswa bagi masing masing perguruan tinggi.

Dengan adanya group atau komunitas pustakawan dengan media komunikasi yang efektif diharapkan layanan koleksi tidak hanya terbatas pada koleksi yang dimiliki suatu perpustakaan tetapi dapat saling share koleksi sehingga dapat memberikan layanan prima kepada pemustaka perguruan tinggi. Komunikasi yang terjalin antar pustakawan perguruan tinggi merupakan network yang penting mengingat kebutuhan informasi yang sangat tinggi di perpustakaan perguruan tinggi harus diimbangi dengan penyediaan koleksi yang memadai di tengah keterbatasan dana, layanan penelusuran informasi sangat efektif dengan mengoptimalkan komunikasi perpustakaan antar perguruan tinggi. Selama ini kartu sakti Forum Komunikasi perguruan tinggi negeri masih terbatas pada ijin penggunaan fasilitaskoleksi belum menyentuh pada bagaimana cara memperoleh koleksi di perpustakaan tersebut. Dengan pemanfaatan media sosial facebook jarak sudah tidak menjadi kendala komunikasi antar perguruan tinggi yang homogen untuk saling mendukung layanan kebutuhan informasi dengan bertukar koleksi atau mendapatkan copy dari koleksi.

\section{Kesimpulan}

Dalam dunia perpustakaan, keterbatasan koleksi dihadapi oleh hampir semua perpustakaan, keterbatasan koleksi disebabkan karena jumlah judul tema tertentu yang beredar di pasaran yang cukup banyak dan tidak mungkin sebuah perpustakaan memiliki semua karena keterbatasan anggaran, padahal permintaan jenis buku baru dari mahasiswa terus meningkat, sehingga pustakawan harus berkreasi untuk menyelesaikan permasalahan keterbatasan koleksi ini. Resources sharing perpustakaan merupakan suatu usaha berbagi sumber daya berupa koleksi perpustakaan yang di dasari oleh kerjasama antar perpustakaan dengan saling berbagi koleksi untuk memenuhi kebutuhan pemustaka. Dalam pelaksa- 
naan resources sharing memerlukan media komunikasi yang efektif dan mampu membentuk suatu komunitas profesi sejenis sehingga lebih optimal dapat dilaksanakan resources sharing, dalam memanfaatkan media sosial untuk resources sharing perpustakaan perguruan tinggi agar efektif diperlukan kesamaan komunitas jurusan/homogen, admin utama, kesepakatan resources sharing, no rekening Bank, Jasa ekspedisi, MoU. Dengan berbagai ketentuan tersebut maka komunikasi antar perpustakaan perguruan tinggi yang homogen atau sejenis akan berjalan dengan baik sehingga dapat saling share koleksi untuk memenuhi kebutuhan pemustaka masing-masing secara optimal.

\section{DAFTAR PUSTAKA}

Boyd, D.M., \& Ellison, N.B. (2007). Social network sites:Definition, history, and scholarship. Journal of Co m p u t e r-Medi a ted Communication, 13(1), 210-230.

Charnigo, L., \& Barnett-Ellis, P. ( 2007 ). Checking Out Facebook.com: The Impact of a Digital Trend on Academic Libraries.Information Technology and Libraries, 26(1), 23-34.

De Rosa, C., Cantrell, J., Havens, A., Hawk, J., Jenkins, L.,Gauder, B., Cellentani, D. (2007). Sharing, privacy andtrust in our networked world: A report to the OCLC Membership. Dublin, OH: OCLC Online Computer Library Center.

Facebook. (2011). Factsheet Retrieved 08/20,2011,http://www.facebook.c om/press/info.php?factsheet https://ptkomunikasi.wordpress.com/201 2/06/11/pengertian-media-sosialperan-serta-fungsinya/. Diakses 5 November 2015

Kaplan, AndreasM.; Michael Haenlein [2010] "Users of the world, unite! The challenges and opportunities of Social Media". Business Horizons 53(1): 59-68

Love Nagojor, 2014, Arti dan Manfaat Jejaring Sosial Facebook Bagi Manusia.http://nagojoronline.blogspot.co.id/2014/02/artidan-manfaat-jejaring-sosial.html diakses 5 November 2015

MacAdam, B. (1998).Creating Knowledge Facilities for Knowledge Work in the Academic Library.Library Hi Tech, 16(1), 9199.

O'Dell, S. (2010). Opportunities and Obligations for Libraries in a Social Networking Age: A Survey of Web 2.0 and Networking Sites..Journal of Library Administration, 50(3), 237-251

Powell, Juliette (2009) 33 million People in the Room: how to create, influence, and run a successful.

Business with Social networking. Pearson $\mathrm{E} \mathrm{d} \mathrm{u} \mathrm{c} \mathrm{a} \mathrm{t}$ i o $\mathrm{n}$, I $\mathrm{n} \mathrm{c}$. https://idv.sagapub.com/cgi/conten $\mathrm{t} / \mathrm{a}$ b s t r a c t / 23/4/266

Seufert, Andreas, Von Krogh Georg and Bach Andrea (1999) Towards knowledge networking.Journal of Knowledge Management Vol. 3 No. 3 1999, 180-190.

Setianingsih, Eko, Zahrotul Uyun, Susatyo Yuwono, 2006, Hubungan Antara Penyesuaian Sosial Dan Kemampuan Menyelesaikan Masalah Dengan Kecenderungan 